I BIENAL LATINOAMERICANA DIDH

\title{
La protección constitucional y convencional de los migrantes
}

\author{
Constitutional and conventional protection of migrants
}

\section{César Landa Arroyo \\ Universidad Católica del Perú}

\begin{abstract}
RESUMEN En el presente artículo se medita sobre la situación de vulnerabilidad de las personas migrantes y los caminos que se deben recorrer para la consideración del derecho fundamental a migrar. En tal sentido, se rescatan los principales estándares interamericanos para su protección, así como la actuación de la justicia constitucional peruana en el actual contexto del ius constitutionale commune. Por último, se hace un balance jurisprudencial del diálogo interjudicial en la garantía de los derechos de los migrantes y se revalora la importancia del ius migrandi frente al caso venezolano.
\end{abstract}

PALABRAS CLAVE Migrantes, control de convencionalidad, ius constitutionale commune, estándares interamericanos, derecho a migrar.

ABSTRACT This article reflects on the situation of vulnerability of migrants and the paths that must be followed in order to consider the fundamental right to migrate. In this sense, the main inter-American standards for their protection are rescued, as well as the performance of the Peruvian constitutional justice in the current context of the ius constitutionale commune. Finally, a jurisprudential balance of the interjudicial dialogue in the guarantee of the rights of the migrants is made and the importance of the ius migrandi in the Venezuelan case is revaluated.

KEYWORDS Migrants, conventionality control, ius constitutionale commune, interAmerican standards, right to migrate. 


\section{Introducción}

No hay democracia sin derecho, ni derecho sin democracia. El poder del Estado proviene del pueblo y las autoridades deben ejercerlo con limitaciones, evitando arbitrariedades e inspirándose en las leyes, la Constitución y los tratados internacionales de derechos humanos. Esa es la base de toda gobernabilidad que pueda calificarse como «democrática».

A pesar de esto, la migración interna e internacional resulta a la fecha restringida por las políticas de seguridad que algunos Estados vienen adoptando a fin de, presuntamente, «asegurar» el orden interno de cada país, pues las personas migrantes - sean cuales fueren los motivos por los cuales deciden movilizarse hacia otro territorio- desafían el andamiaje jurídico y la institucionalidad democrática de los Estados receptores, basados en una legitimidad política de la soberanía de los Estados. Sin embargo, ésta no puede desconocer los derechos humanos de los migrantes.

Este grupo en situación de vulnerabilidad tiene derechos humanos universales de goce y de ejercicio en cualquier territorio. En el actual contexto de la migración venezolana a diferentes regiones de América Latina, ${ }^{1}$ así como de la migración centroamericana hacia Estados Unidos, ${ }^{2}$ se demuestra la especial trascendencia de derechos como libre tránsito, residencia, asilo, unidad familiar, nacionalidad y debido proceso, así como los derechos económicos, sociales y culturales.

En este sentido, es necesario advertir los principales estándares interamericanos de protección de los migrantes y la importancia que estos han tenido al momento de resolver casos en la judicatura constitucional peruana, en el marco del llamado ius constitutionale commune, y que resultan de similar relevancia para los demás altos tribunales de la región.

Lo señalado nos permitirá reflexionar sobre el debate doctrinario en torno al reconocimiento del derecho fundamental humano a migrar, el cual si bien en un principio fue ejercido por las antiguas potencias occidentales a fin de legitimar las conquistas y las colonizaciones (Ferrajoli, 2019: 34), en la actualidad merece ser repe-

1. «Refugiados y migrantes de Venezuela superan los cuatro millones: ACNUR y OIM», Oficina del Alto Comisionado de las Naciones Unidas para los Refugiados, 7 de junio de 2019, disponible en https:// bit.ly/3fNWfsf. Los países latinoamericanos acogen a la gran mayoría de venezolanos: Colombia ha recibido alrededor de 1,3 millones, seguido por Perú con 768.00o, Chile con 288.00o, Ecuador con 263.00o, Argentina con 130.000 y Brasil con 168.00o. México y los países de América Central y el Caribe también albergan un gran número de refugiados y migrantes de Venezuela.

2. María Rodríguez, «Estadísticas generales de inmigración en Estados Unidos», Thought Co., 9 de febrero de 2019, disponible en https://bit.ly/2E1iRs3. Se señala que para finales del año 2018 había en Estados Unidos alrededor de 44 millones de inmigrantes, entre regulares e irregulares. Esta cifra supone que el 13,5\% de la población proviene de otros lugares del mundo, y que uno de cada cinco inmigrantes elige a Estados Unidos como su destino final. 
sando y protegido en el ámbito doméstico e interamericano, en el contexto de flujos migratorios masivos que se desarrollan en la región, para permitir una migración libre y segura de la ciudadanía.

\section{Estándares interamericanos de protección de los derechos de los migrantes}

Los derechos humanos son universales porque la persona humana, sin distinción de su origen nacional, nace libre e igual en dignidad. Así, nadie puede ser discriminado por razones de raza, sexo, color de piel, idioma, origen o cualquier otra índole, que constituyen las clásicas «categorías sospechosas» de discriminación.

La prohibición de discriminación se encuentra en la Declaración Universal de los Derechos Humanos; en los pactos regionales, como la Convención Europea de Derechos Humanos, la Convención Americana de Derechos Humanos y la Carta Africana de derechos Humanos; así como el Pacto Internacional de Derechos Civiles y Políticos, el Pacto Internacional de Derechos Económicos, Sociales y Culturales, la Convención contra la Tortura, la Convención Internacional contra la Discriminación Racial, y la Convención para el Empleo y Familiares de los Migrantes, entre muchos otros instrumentos internacionales.

El Sistema Interamericano de Derechos Humanos se ha encargado de promover y garantizar la eficacia del mandato de igualdad y no discriminación de las personas migrantes contenido en el artículo 1.1 de la Convención Americana sobre Derechos Humanos, así como el artículo 24, a través de diversos informes temáticos, opiniones consultivas y casos contenciosos emitidos por la Comisión Interamericana de Derechos Humanos (CIDH) y la Corte Interamericana de Derechos Humanos (Corte IDH).

La tasa más alta de migración en América Latina es hacia los Estados Unidos, que llega a 75\% del total que emigra de la región; por algo hay más de 59 millones de latinos, según el censo del año 2016, de los cuales 60\% son mexicanos. Ello ha llevado a una corriente migratoria irregular que ha significado una serie de tratos discriminatorios y degradantes y que ha servido para un importante pronunciamiento de la Corte IDH a través de la OC-18/03. ${ }^{3}$

México formuló una consulta ante la Corte IDH sobre los derechos de los trabajadores migrantes, pues parte de la legislación de los Estados Unidos los trataba de manera discriminatoria, en especial en lo referido al ámbito laboral. Así, la Alta Corte consideró necesario iniciar su respuesta señalando que todos los ciudadanos tienen derecho a ser tratados de manera equitativa y sin distinciones injustificadas o arbitrarias, pues es un deber ineludible de los Estados el respetar el principio de la igualdad

3. «Condición jurídica y derechos de los migrantes indocumentados», Corte Interamericana de Derechos Humanos, Opinión Consultiva OC-18/o3, serie A núm. 18, 17 de septiembre de 2003. 
y no discriminación, en tanto es parte del ius cogens y, por ende, cualquier tratado o acto jurídico que vaya en contra de este será declarado nulo.

La Corte IDH decidió pronunciarse primordialmente por la situación de los «trabajadores inmigrantes indocumentados», es decir, de aquellas personas que llegan a un país a trabajar en forma irregular, sin las autorizaciones ni permisos respectivos. Estas personas están en situaciones graves, que los fuerzan a salir de sus países de origen para buscar mejoras económicas en otros lugares. Lamentablemente, su situación de vulnerabilidad aumenta en forma considerable cuando se toma en cuenta que su trabajo suele ser infravalorado en el mercado laboral, so pretexto de su condición de irregularidad. Así, muchas empresas o particulares se aprovechan de su apremiante situación para buscar provecho propio, con condiciones laborales adversas en extremo.

La condición de irregularidad no puede anular los derechos humanos inherentes a la condición del trabajador, pues estos derechos son consecuencia de la relación laboral existente. Por más que la persona esté en el país de manera irregular, esta situación no amerita o justifica tratos que atenten contra su dignidad. Por ello, no es justificable la contratación con condiciones laborales menos favorables frente a terceros que sí cuentan con una situación jurídica estable, sean nacionales u otros extranjeros. Así lo estableció de manera categórica la Corte IDH cuando señaló:

La calidad migratoria de una persona no puede constituir, de manera alguna, una justificación para privarla del goce y ejercicio de sus derechos humanos, entre ellos los de carácter laboral. El migrante, al asumir una relación de trabajo, adquiere derechos por ser trabajador, que deben ser reconocidos y garantizados, independientemente de su situación regular o irregular en el Estado de empleo. Estos derechos son consecuencia de la relación laboral (OC-18/03, fundamento 134).

La Corte IDH recuerda que, por supuesto, nadie está en obligación de contratar a una persona que responda a estas características. Empero, si decide hacerlo, debe respetar los derechos laborales de los migrantes indocumentados que tengan un vínculo de trabajo con él o ella, pues se convierten en titulares de los derechos correspondientes, sin que exista posibilidad de discriminación por su situación irregular.

De esta manera, la Alta Corte, a través de su opinión consultiva, reforzó el principio de igualdad y no discriminación en el ámbito laboral y en específico consideró la situación de migración irregular de los trabajadores de la región. Con posterioridad emitiría diversas opiniones consultivas de similar importancia, como la OC-21/14 sobre la protección de las niñas, niños y adolescentes en el marco de la movilidad humana, ${ }^{4}$

4. «Derechos y garantías de niñas y niños en el contexto de la migración y/o en necesidad de protección internacional», Corte Interamericana de Derechos Humanos, Opinión Consultiva OC-21/14, serie A núm. 21, 19 de agosto de 2014. 
y la OC-25/18, en la cual desarrolló el contenido convencional del derecho humano a buscar y recibir asilo, así como sus diversas modalidades, en el derecho internacional. ${ }^{5}$

Ahora bien, sin perjuicio de la importancia de las decisiones de la Corte IDH en ejercicio de su competencia consultiva, debemos rescatar también los informes emitidos por la Comisión Interamericana en el reconocimiento de la situación de especial vulnerabilidad de las personas migrantes y en la determinación de estándares para su protección efectiva.

Es el caso, por ejemplo, del informe temático «Movilidad humana: estándares del Sistema Interamericano de Derechos Humanos», publicado el 31 de diciembre de 2015. En este informe, la CIDH aborda cuestiones de indudable relevancia, como la movilidad humana, la migración forzada en las Américas y las distintas categorías de especial protección, como los refugiados, solicitantes de asilo, víctimas de trata de personas, apátridas, migrantes internos y desplazados internos.

Por otro lado, los estándares interamericanos de protección de los derechos de los migrantes también están conformados por los principales pronunciamientos emitidos por la Corte IDH en el marco de su competencia contenciosa. Tres ejemplos relevantes de la amplia jurisprudencia de la Alta Corte lo conforman los casos Velez Loor con Panamá, Nadege Dorzema y otros con República Dominicana y Pacheco Tineo con Bolivia.

El caso Vélez Loor con Panamá involucró a un ciudadano ecuatoriano, quien en 2002 fue retenido en el puesto policial de Tupiza (Panamá) por no contar con la documentación necesaria para permanecer en el país. La directora de migración dictó orden de detención en su contra, por lo que fue trasladado a un centro penitenciario. Se resolvió imponerse una pena de dos años de prisión por el quebrantamiento de las disposiciones del Decreto Ley sobre Migración. Después fue trasladado al centro penitenciario La Joyita. Al cabo de un año, la directora de migración resolvió dejar sin efecto la pena impuesta. Finalmente fue deportado hacia Ecuador, donde el señor Vélez Loor denunció haber sido víctima de actos de tortura y malos tratos en los diversos centros penitenciarios de Panamá.

La Corte IDH consolidó el famoso estándar relacionado a que el ingreso irregular a un país no constituye delito. Asimismo, evaluó la violación del derecho a la libertad personal, a la luz de la orden de privación de libertad arbitraria y la falta de recursos disponibles para cuestionar la legalidad de su detención. Asimismo, observó que el

5. «La institución del asilo y su reconocimiento como derecho humano en el Sistema Interamericano de Protección (interpretación y alcance de los artículos 5, 22.7 y 22.8, en relación con el artículo 1.1 de la Convención Americana sobre Derechos Humanos)», Corte Interamericana de Derechos Humanos, Opinión Consultiva OC-25/18, serie A núm. 25, 30 de mayo de 2018.

6. Sentencia del caso Vélez Loor con Panamá, Corte Interamericana de Derechos Humanos, excepciones preliminares, fondo, reparaciones y costas, serie C núm. 218, 23 de noviembre de 2010. 
procedimiento administrativo sancionatorio mediante el cual se le privó la libertad a Vélez Loor no cumplió con distintas garantías, como el derecho a ser oído y a contar con asistencia técnica letrada. Del mismo modo, la Corte advirtió que Vélez Loor no tuvo oportunidad de comunicarse con el consulado de su país ni tuvo acceso efectivo a la asistencia consular como componente del derecho a la defensa.

La Corte IDH consideró que el artículo 67 del Decreto Ley 16 emitido en sede interna era irrazonable y desproporcional (inconvencional), pues consagraba una sanción de carácter punitivo para los extranjeros que eludieran una orden de deportación previa y, por ende, daba lugar a detenciones arbitrarias. Además, el Tribunal Interamericano enfatizó la importancia de que los migrantes sean detenidos en establecimientos específicamente destinados a tal fin, que sean acordes a su situación legal y no en prisiones comunes.

Por su lado, en Nadege Dorzema y otros, ${ }^{7}$ la Corte IDH conoció el caso de treinta ciudadanos haitianos, entre los cuales se encontraban un niño y una mujer en estado de gravidez, que abordaron un camión rumbo a Santiago de los Caballeros en territorio dominicano. El camión pasó por el primer puesto de control sin ser detenido; sin embargo, al llegar al segundo puesto de control, un grupo de militares hizo señales para que se detengan, por lo que el camión desvió su marcha y se dirigió al poblado de Copey. En tal contexto, cuatro militares pertenecientes al Destacamento Operativo de Fuerza Fronteriza abordaron su patrulla e iniciaron la persecución del vehículo, que terminó con la volcadura del camión con muertos y heridos, a quienes detuvieron y llevaron a la frontera para expulsarlos a Haití.

La Corte IDH declaró violados los derechos a la vida e integridad personal de las víctimas, en mérito al excesivo uso de la fuerza militar y las ejecuciones extrajudiciales cometidas en perjuicio de las personas haitianas. Asimismo, se pronunció sobre la libertad personal y el derecho a la libre circulación y residencia, pues no se respetó ni garantizó el debido proceso en el marco de su detención, y sufrieron expulsión colectiva sin seguir los estándares internacionales en la materia ni los procedimientos previstos en la normativa interna.

En este punto, es importante recordar que la Corte IDH mencionó que un proceso que pueda resultar en la expulsión o deportación de un extranjero debe de garantizar, como mínimo:

i) ser informado expresa y formalmente de los cargos en su contra y de los motivos de la expulsión o deportación. Esta notificación debe incluir información sobre sus derechos, tales como:

a. la posibilidad de exponer sus razones y oponerse a los cargos en su contra;

7. Sentencia del caso Nadege Dorzema y otros con República Dominicana, Corte Interamericana de Derechos Humanos, fondo, reparaciones y costas, serie C núm. 251, 24 de octubre de 2012. 
b. la posibilidad de solicitar y recibir asistencia consular, asesoría legal y, de ser el caso, traducción o interpretación;

ii) en caso de decisión desfavorable, debe tener derecho a someter su caso a revisión ante la autoridad competente y presentarse ante ella para tal fin, y

iii) la eventual expulsión solo podrá efectuarse tras una decisión fundamentada conforme a la ley y debidamente notificada (fundamento 175).

Por último, el caso Pacheco Tineo y otros $^{8}$ también ha sido de vital importancia en la línea jurisprudencial interamericana. En 2001, los miembros de la familia peruana Pacheco Tineo ingresaron a Bolivia de manera irregular. Las autoridades de migración tomaron nota de su situación migratoria y dispusieron medidas a fin de proceder a su expulsión al Perú. El señor Pacheco solicitó al Estado el reconocimiento del estatuto de refugiados a favor de él y los miembros de su familia; sin embargo, la solicitud fue rechazada. De tal manera, por decisión adoptada por las autoridades migratorias, la familia Pacheco Tineo fue devuelta a Perú.

En dicho caso, la Corte IDH desarrolló el contenido del derecho de buscar y recibir asilo, según el artículo 22.7 de la Convención Americana, lo cual no implicaba que debiera reconocerse el estatuto de refugiado a la persona solicitante, pero sí que la solicitud sea tramitada de acuerdo con el debido proceso. En tal sentido, la Corte advirtió que, en el caso en concreto, la familia Pacheco Tineo no contó con posibilidad alguna de conocer mínimamente las decisiones que habían sido proferidas respecto de su solicitud y su situación migratoria, pues la familia fue expulsada al día siguiente de la emisión de una resolución que no fue notificada y fue expedida en un plazo en exceso corto.

De tal manera, este caso es de especial importancia, pues la Corte IDH determinó un grupo de obligaciones a cargo de los Estados a fin de respetar las garantías del debido proceso en el trámite de reconocimiento del estatus de refugiado: acceso a asesoría y representación legal, incluyendo los servicios de un intérprete competente; respetar el debido procedimiento, que incluye una entrevista personal; la resoluciones deben estar debidamente fundamentadas; en las solicitudes de asilo debe garantizarse la protección de datos y la confidencialidad de la información; de rechazarse su solicitud, debe recibir información para recurrir en un plazo razonable; y la revisión debe tener efecto suspensivo y permitir la permanencia del solicitante hasta que la autoridad tome la decisión definitiva.

Sin perjuicio de los estándares interamericanos mencionados, es importante tener en cuenta la Resolución 2/18, aprobada el 2 de marzo de 2018 en Bogotá, mediante la cual la CIDH se pronunció sobre uno de los problemas de mayor preocupación actual: la migración forzada de personas venezolanas.

8. Sentencia del caso Familia Pacheco Tineo con Bolivia, Corte Interamericana de Derechos Humanos, excepciones preliminares, fondo, reparaciones y costas, serie C núm. 272, 25 de noviembre de 2013. 
En tal sentido, la Comisión atendió a la grave crisis política, económica y social de Venezuela bajo el mandato de Nicolás Maduro, y a la dinámica migratoria venezolana en búsqueda de alimentos y medicamentos, lo cual se reflejaba en el alto número de migrantes irregulares y solicitantes de asilo en la región. Esta resolución es de especial importancia, ya que demuestra la preocupación por la implementación de políticas y medidas migratorias con mayores restricciones en perjuicio de las personas venezolanas en América Latina, y exhorta a los Estados a adoptar medidas como: i) el reconocimiento de la condición de refugio a personas venezolanas de acuerdo con la Declaración de Cartagena sobre Refugiados de 1984; ii) la adopción de respuestas colectivas de protección de las personas venezolanas; iii) el respecto del principio y derecho a la no devolución; iv) la implementación de mecanismos que permitan identificar a las personas que se encuentren en situación de vulnerabilidad; v) no criminalizar la migración de personas venezolanas e implementar medidas dirigidas a la lucha contra la discriminación y xenofobia, entre otras.

Dicha resolución, si bien no es estrictamente vinculante, constituye un llamado a la comunidad internacional a una respuesta regional e internacional -respetuosa de los derechos humanos- a la migración forzada de personas venezolanas y en el marco de la denominada «responsabilidad compartida», que incluso ha sido utilizada como parámetro de interpretación en la emisión de medidas cautelares por la misma CIDH. ${ }^{9}$

En virtud de lo mencionado, se procederá a continuación a evaluar el impacto que han tenido dichos estándares interamericanos en algunos casos resueltos por la judicatura constitucional peruana en el marco del ius constitutionale commune y el control de convencionalidad ejercido en la protección de los migrantes.

\section{El Tribunal Constitucional peruano y la protección de los migrantes}

Desde mediados del siglo XIX, las corrientes migratorias en el Perú fueron esporádicas pero muy definidas. Por ejemplo, para colonizar la selva central se promovió por parte del Estado el ingreso de 13.000 familias alemanas; a fin de suplir la abolición de la mano de obra indígena y la esclavitud de los afroperuanos, el Estado entregó en consignación la contratación de mano de obra china, los llamados «culíes», de los cuales alrededor de 100.000 llegaron a inmigrar. También se produjeron importantes flujos migratorios espontáneos de italianos, británicos y franceses, quienes contribuyeron con su arte, oficio o empresa a la modernización del Perú.

En el siglo XX, dados los conflictos nacionales, internacionales y mundiales, se iniciaron importantes corrientes migratorias, en particular desde Japón, como tam-

9. Convención Interamericana de Derechos Humanos, Resolución 81/2018, medida cautelar 4902018, M. B. B. P., respecto de Panamá, 15 de octubre de 2018. 
bién de menor envergadura por árabes palestinos, así como de otros países europeos del Este. Frente a ello, a partir de 1930 los Gobiernos militares del Perú dispusieron la prohibición de ingreso al país de comunistas, anarquistas o nihilistas. A su vez, durante la Segunda Guerra Mundial se produjo la deportación de japoneses a Estados Unidos y la expropiación de las empresas alemanas.

Durante las décadas de los setenta y ochenta, los regímenes militares de América Latina, entre ellos el del Perú, reprimieron con mayor o igual impunidad a los extranjeros por medio del «plan Cóndor». Hubo casos de violaciones de derechos humanos que, durante los procesos democráticos de finales del siglo XX, pudieron ser juzgados y en algunos casos reparados, tanto a nivel de los tribunales nacionales y extranjeros como del Sistema Interamericano de Derechos Humanos.

Para el Perú, el fenómeno migratorio del siglo XXI es la migración venezolana, porque marca un hito para el Estado democrático y social, debido al volumen de familias que ingresan por razones humanitarias por causa de la grave crisis política y económica por la que atraviesa Venezuela. Como consecuencia, han emigrado más de 4 millones de venezolanos, cerca de 800.000 al Perú. ${ }^{10}$ Esta situación ha generado un debate público y social sobre los derechos de los migrantes, el que además se ha empezado a judicializar.

A continuación, se presentan tres casos emblemáticos en el ámbito constitucional, desde la vigencia de la transición democrática, que de cierto modo revelan la recepción del derecho internacional de los derechos humanos en sede interna y abre caminos en una reflexión sobre la libertad de migrar como derecho fundamental.

El caso del ciudadano chino Wong Ho Wing es paradigmático. ${ }^{11}$ Fue procesado en China por delito contra el patrimonio del Estado, pero huyó al Perú y fue detenido en Lima por una orden de detención de la Interpol en 2008. De este modo, se inició el proceso de extradición sobre la base de un tratado internacional de cooperación recíproca judicial entre el Perú y China. Ho Wing recurrió ante el Tribunal Constitucional por la decisión de la Corte Suprema del Perú de extraditarlo para que sea procesado por el delito de contrabando, ya que peligraba su vida por pena capital contra delitos patrimoniales contra el Estado. En 2010, el Tribunal Constitucional en mayoría declaró fundada la demanda, basado en los argumentos del demandante.

Sin embargo, el interesado, en simultáneo, recurrió al presidente de la Corte IDH, quien emitió una medida provisional para evitar que el Estado llevara a cabo la extradición; y a la Comisión Interamericana de Derechos Humanos, la que también expidió una medida cautelar de no extradición.

10. Oficina Internacional de Migración, «Reporte Mundial Migratorio 2020», disponible en https:// bit.ly/3gTBIny.

11. Sentencia del caso Wong Ho Wing con Perú, Corte Interamericana de Derechos Humanos, excepción preliminar, fondo, reparaciones y costas, serie C núm. 297, 30 de junio de 2015. 
Por su parte, el Gobierno chino acreditó que el procesado no era pasible de la aplicación de la pena de muerte en caso de ser condenado, debido a que esta pena había sido abolida del Código Penal para ese delito el 25 de febrero del 2011. No obstante, el Tribunal Constitucional se pronunció en mayoría en un nuevo habeas corpus presentado por Ho Wing, señalando que no estaba acreditada la aplicación retroactiva de la ley penal, aun cuando la ley fuera más favorable al reo; ello, a pesar de que entre los principios del Código Penal de China se encuentra el de la aplicación de la ley benigna al reo.

Finalmente, la Corte IDH, al resolver el proceso que inició la Comisión a favor de Ho Wing contra el Estado peruano, falló en 2015 declarando que habiéndose acreditado que no existía el peligro de la aplicación de la pena de muerte, correspondía a la justicia peruana resolver dicha controversia, la misma que en 2016 permitió al Tribunal Constitucional validar la resolución de la Corte Suprema de Justicia sobre la constitucionalidad de la extradición. Esto dio lugar a la extradición de Ho Wing a China, pero con el mandato de supervisión del cumplimiento de las condiciones del proceso, detención y condena.

Por su lado, el caso de Mesquita Oliviera también resulta de especial relevancia en materia de protección del debido proceso de las personas migrantes. ${ }^{12} \mathrm{El}$ Tribunal Constitucional se pronunció sobre el caso del ciudadano brasileño Jesús de Mesquita Oliviera, casado con una peruana y con una hija peruana, el cual recibió una orden de salida obligatoria del país en el marco de un procedimiento migratorio, y se le impidió su reingreso a pesar de su arraigo y vínculo familiar, por violar la antigua Ley de Extranjería (Decreto Legislativo 703), debido a que se encontraba con una visa de turista vencida largamente.

Este caso es de particular importancia, pues el Tribunal Constitucional recogió los estándares fijados en el caso de Pacheco Tineo, abordado en párrafos anteriores. En tal sentido, el Tribunal dispuso que era exigible reconocer a los extranjeros en situación irregular las siguientes garantías mínimas: el derecho a ser informado expresa y formalmente de los motivos de la sanción administrativa; el derecho a exponer y acreditar razones que lo asistan en contra de la sanción administrativa impuesta; solicitar y recibir asesoría legal; en caso de una decisión desfavorable, el derecho a someter su caso a revisión ante una autoridad competente e imparcial; y que la eventual expulsión solo podrá efectuarse tras una decisión fundamentada conforme a la ley y debidamente notificada.

En la actualidad, el Decreto Legislativo 1.350 (Nueva Ley de Migraciones) y su reglamento regulan la migración en clave del goce y ejercicio de los derechos y deberes de las personas extranjeras en el Perú, impulsando el despliegue de actividades económicas formales sujetas al pago de impuestos, la regularización migratoria y la atención a las personas en situación de vulnerabilidad.

12. Tribunal Constitucional del Perú, Expediente 02744 2015-PA/TC. 
Por último, un caso pendiente de decisión por el Tribunal Constitucional es el de pasaporte y visa venezolana. ${ }^{13}$ La Coordinadora Nacional de Derechos Humanos interpuso contra el ministro del Interior un habeas corpus a favor de los migrantes venezolanos que no cuentan con pasaporte, por impedirles el ingreso al territorio nacional, dado que esto viola el derecho a la libertad de tránsito, a solicitar refugio, a la igualdad y no ser discriminado, así como el derecho de los niños y niñas a migrar.

La jueza de primera instancia consideró que la Resolución de Superintendencia 000270-2018, que dispone exigir la presentación de pasaporte vigente a las personas de nacionalidad venezolana para efectos del control migratorio de ingreso al territorio nacional, vulneró el derecho a la libertad de tránsito de los ciudadanos venezolanos que no cuenten con pasaporte, por lo que declaró fundada la demanda de habeas corpus en dicho extremo.

En segunda instancia, la Corte Superior de Justicia de Lima planteó que la controversia se resolvería determinando si existe o no transgresión del derecho a la libertad de tránsito. Para tal efecto, recordó que el Estado está facultado para reglar, controlar y condicionar la entrada y admisión de extranjeros. ${ }^{14}$

En ese sentido, los ciudadanos venezolanos que pretenden migrar al Estado peruano deben cumplir con satisfacer los presupuestos establecidos con tal fin, toda vez que el derecho al libre tránsito no es irrestricto. Por tanto, tratándose de extranjeros que buscan ingresar por la frontera, empero aún no se encuentran dentro, no resultan de aplicación las normas de derecho interno.

De este modo, la Corte Superior señaló que no es amparable a través de un habeas corpus el acto de ingresar a otro país «sin ningún tipo de limitación», porque no está reconocido como derecho en ningún instrumento internacional, ni en la OC-18/o3 ni en la OC-21/14 de la Corte IDH, así como tampoco en ordenamiento jurídico del país. Esto, debido a que los Estados conservan la potestad soberana para aceptar o rechazar el ingreso de una persona a su territorio en función de lo que establezca su normatividad migratoria. Esta decisión ha sido cuestionada por el demandante vía recurso de agravio constitucional y, como se mencionó, se encuentra pendiente de decisión.

Es importante mencionar que la Coordinadora Nacional de Derechos Humanos interpuso una nueva demanda de habeas corpus, esta vez respecto de la exigencia de visa a las personas venezolanas que comenzó a regir el 15 de junio del 2019, por lo que el reto en materia de control de convencionalidad en favor de las personas migrantes continúa pendiente en sede judicial y constitucional.

En virtud de los casos mencionados, se puede apreciar una recepción continua de

13. Quinto Juzgado Penal para Procesos con Reos Libres y Cuarta Sala Penal Especializada para Procesos con Reos Libres, Expediente 06488-2018-0-1801-JR-PE-05.

14. Tribunal Constitucional del Perú, STC 2876-2005-PHC/TC, foja 12. 
diversos estándares interamericanos en sede constitucional en el caso peruano, sobre todo en materia de debido proceso, sin perjuicio de que también existen resistencias en torno a la libertad de tránsito - y si vamos un poco más lejos, en el caso venezolano, al derecho a migrar - de las personas migrantes. Por tanto, el Estado peruano deberá reflexionar sobre la situación de especial vulnerabilidad de este colectivo, y adoptar respuestas que pueden girar en torno al enfoque de la política migratoria, las leyes migratorias o decisiones amparadas en el control de convencionalidad.

\section{El ius constituionale commune en América Latina y los caminos hacia el derecho a migrar}

Es importante el diálogo interjudicial que debe existir entre las altas cortes de la región, los órganos de protección supranacional y los tribunales internos. Así, la apertura y recepción hacia los estándares interamericanos de protección por los Estados constitucionales y democráticos de derecho merece ser continua y siempre favorable a la máxima protección de los derechos fundamentales, como expresión propia de lo que en la región se ha denominado ius constitutionale commune..$^{15}$

El caso de la especial situación de vulnerabilidad de las personas migrantes revela los patrones y estructuras de discriminación que han sufrido durante mucho tiempo y que persisten debido a la ausencia de comprensión de los Estados respecto de la facultad soberana de fijar sus políticas migratorias con límites en los derechos humanos, propia de cualquier Estado que pueda ser denominado «democrático».

Los flujos masivos de migración como el caso venezolano no solo llaman la atención respecto de los desafíos en el activismo judicial y el control de convencionalidad, sino que sobre todo invitan a reflexionar sobre la necesaria presencia de derechos como la libertad de migrar, que se encuentra ausente en muchas cartas fundamentales de la región ${ }^{16}$ - como la peruana-, o en las leyes especiales de migración, ${ }^{17}$ y que definitivamente provienen desde el derecho natural.

Es cierto que constituye una labor destacable por la administración de justicia a nivel supranacional la fijación de estándares en materia de debido proceso, personalidad jurídica, integridad personal, igualdad y no discriminación, circulación y residencia, entre otros. Sin embargo, en protección de las personas migrantes $-\mathrm{y}$, de similar modo, el control de convencionalidad ejercido por los tribunales internos de la región acogiendo los estándares interamericanos en la solución de controversias jurídicas-, lo cierto es que los caminos para la protección efectiva de sus derechos requieren esfuerzos que vayan más allá y visibilicen el ius migrandi.

15. Me he referido sobre este aspecto en Landa (2016: 104-107).

16. Un caso excepcional es el artículo 40 de la Constitucional Nacional de Ecuador.

17. Obsérvese el artículo 4 de la Ley 25.871 de la República de Argentina. 
Lo señalado implica no solo medidas desde el ámbito jurisdiccional, sino también de los poderes Ejecutivo y Legislativo, quienes se encuentra obligados a armonizar las normas internas con el derecho internacional a fin de lograr una revaloración de los derechos de las personas migrantes en una lógica de fronteras abiertas y cooperativas en la región.

\section{Conclusión}

En el ámbito interamericano, presenciamos que los actuales patrones de migraciones masivas y forzadas - como claro ejemplo es el caso venezolano- requieren una reflexión sobre la consagración y protección constitucional y convencional de un derecho fundamental a migrar, pues al final esto no solo irradiará sus efectos en las políticas migratorias locales, sino que también reforzará y ampliará la jurisprudencia migratoria de la jurisdicción nacional e internamericana, lo que abrirá puertas a una sociedad más inclusiva y a la consolidación del ius constitutionale commune.

\section{Referencias}

Ferrajoli, Luigi (2019). «Políticas contra los migrantes y crisis de la civilización jurídica». Revista Peruana de Derecho Constitucional, 18: 182-193. Disponible en https://bit.ly/2PTfJBy.

LANDA, César (2016). Convencionalización del derecho peruano. Lima: Palestra.

\section{Sobre el autor}

CÉsar Landa Arroyo es expresidente del Tribunal Constitucional del Perú. Catedrático de la Pontificia Universidad Católica del Perú y la Universidad Nacional Mayor de San Marcos. Su correo electrónico es clanda@pucp.edu.pe. (D) https://orcid. org/0000-0003-0801-8873. 
El Anuario de Derechos Humanos es una publicación semestral de referencia y consulta en materia de derechos humanos y campos afines. Busca ser un espacio de discusión de los temas centrales en el ámbito nacional e internacional sobre derechos humanos. Es publicado desde 2005 por el Centro de Derechos Humanos de la Facultad de Derecho de la Universidad de Chile.

\author{
EDITORA GENERAL \\ Claudia Iriarte Rivas \\ ciriarter@derecho.uchile.cl \\ EDITORA DE ESTE NÚMERO \\ Liliana Galdámez Zelada \\ lgaldamez@derecho.uchile.cl \\ SITIO WEB \\ anuariocdh.uchile.cl \\ CORREO ELECTRÓNICO \\ anuario-cdh@derecho.uchile.cl \\ LICENCIA DE ESTE ARTÍCULO
}

Creative Commons Atribución Compartir Igual 4.o Internacional

\author{
कै \\ La edición de textos, el diseño editorial \\ y la conversión a formatos electrónicos de este artículo \\ estuvieron a cargo de Tipográfica \\ (www.tipografica.io)
}

